\section{Elastography of focal testicular lesions: current concepts and utility}

\author{
Cheng Fang, Dean Y. Huang, Paul S. Sidhu \\ Department of Radiology, King's College Hospital, London, UK
}

As a relatively new sonographic technique, tissue elastography has emerged as a qualitative and potentially quantitative adjunctive tool to provide additional information on tissue stiffness, aiming to further improve diagnostic confidence in discriminating benign from malignant focal testicular lesions. The purpose of this review is to provide an overview of the elastography techniques used to assess focal testicular lesions and their typical appearance on tissue elastography.

Keywords: Ultrasonography; Testicular neoplasms; Elasticity imaging techniques; Leydig cells tumor; Epidermal cyst

\section{Introduction}

Traditionally, assessment of the testis with B-mode and color Doppler ultrasonography (US) has been the main workhorse for identifying and characterising focal testicular lesions owing to its superb spatial resolution of anatomical details and the superficial location of the testis. B-mode US accurately identifies the size, shape, location (intra- or extra-testicular), and pattern of echogenicity of lesions. Colour Doppler US assesses the presence and pattern of vascularity in the lesion to increase diagnostic confidence, with disorganized vascularity suggesting a malignant lesion and avascularity or iso-vascularity compared to the background testicular tissue suggesting a benign lesion. Relatively new sonographic techniques such as tissue elastography have emerged as a qualitative and potentially quantitative adjunctive tool to provide additional information on tissue stiffness, aiming to further improve diagnostic confidence in discriminating benign from malignant lesions, under the assumption that malignant lesions are "harder" than benign lesions. The purpose of this review is to provide an overview of the elastography techniques used to assess focal testicular lesions and their typical appearance on tissue elastography.

\section{Elastography Techniques}

\section{Strain Elastography}

There are two types of elastography techniques, commonly referred to as strain and shear wave elastography. Strain elastography measures the tissue strain response when a compression force is applied to the tissue. The strain elastography technique was first used in clinical practice in the form of a proprietary technique known as real-time elastography (RTE, Hitachi Medical Corp., Tokyo, Japan). RTE evaluates the relative strain response of the tissue, including the region of interest and

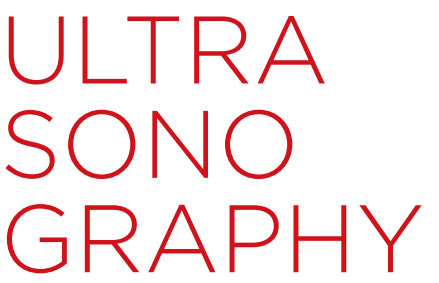

REVIEW ARTICLE

https://doi.org/10.14366/usg. 18062 pISSN: 2288-5919 - elSSN: 2288-5943

Ultrasonography 2019;38:302-310

Received: November 1, 2018

Revised: January 28, 2019

Accepted: January 30, 2019

Correspondence to:

Cheng Fang, FRCR, Department of

Radiology, King's College Hospital, Denmark Hill, London SE5 9RS, UK

Tel. +44-2032994164

Fax. +44-2032993157

E-mail: chengfang@nhs.net

\begin{abstract}
This is an Open Access article distributed under the terms of the Creative Commons Attribution NonCommercial License (http://creativecommons.org/ licenses/by-nc/4.0/) which permits unrestricted noncommercial use, distribution, and reproduction in any medium, provided the original work is properly cited.
\end{abstract}

Copyright (C) 2019 Korean Society of Ultrasound in Medicine (KSUM)

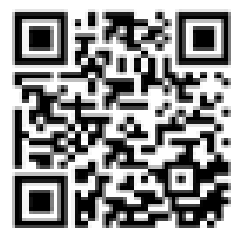

How to cite this article:

Fang C, Huang DY, Sidhu PS. Elastography of focal testicular lesions: current concepts and utility. Ultrasonography. 2019 0ct;38(4):302310.

e-ultrasonography.org 
the adjacent tissue, to mechanical stress by analyzing echo signals before and after light compression is applied by the transducer. The strain response of the tissue is converted into an elastic modulus image known as an elastogram and displayed as a color-coded map, superimposed on to the conventional B-mode image. The color spectrum ranges from red to blue, representing soft to hard tissue stiffness. The visual elasticity score (VES), according to which the elastographic appearance is graded on a 5- or 6-point scale, adapted from breast elastography [1], has been used to categorize the stiffness of testicular abnormalities (Table 1) [2-4]. A VES cut-off of 3 may be used to classify testicular lesion stiffness as "hard" (VES $>3$ ) or "soft" (VES $\leq 3)$. In addition to the visual map, the strain ratio (SR) between the abnormal testicular tissue and adjacent normal testicular parenchyma can be calculated as a semiquantitative numerical index. It is only a semi-quantitative method, as it is used to assess the relative tissue elasticity of the region of

Table 1. Visual elasticity scores

\begin{tabular}{cl}
$\begin{array}{c}\text { Visual } \\
\text { elasticity score }\end{array}$ & \multicolumn{1}{c}{ Description } \\
\hline 1 & $\begin{array}{l}\text { The lesion is almost completely green but with some } \\
\text { red spots. }\end{array}$ \\
3 & $\begin{array}{l}\text { The entire lesion is homogeneously green. } \\
\text { The lesion is almost completely green but with some } \\
\text { small blue spots. } \\
\text { The lesion is green at the periphery with a central blue } \\
\text { area. }\end{array}$ \\
& $\begin{array}{l}\text { The lesion is almost completely blue with central } \\
\text { small green or red areas. }\end{array}$ \\
\hline
\end{tabular}

Source: Konstantatou et al. J Ultrasound Med 2019;38:223-232 [10].

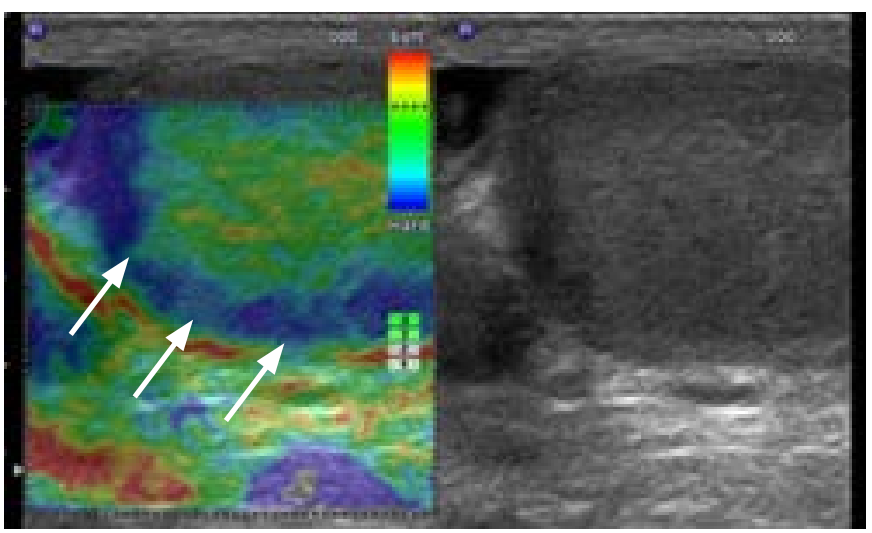

A interest and background tissue, rather than the absolute tissue elasticity.

\section{Shear Wave Elastography}

Shear wave elastography differs from strain elastography, as it is a quantitative method of assessing tissue elasticity by measuring the speed of acoustic radiation force impulse-induced shear waves traveling in the tissue of interest [5]. Shear waves are a type of mechanical wave whose propagation speed within the soft tissue can be measured. Shear wave velocities are measured by the scanner in $\mathrm{m} / \mathrm{sec}$, and they can be converted to the Young modulus of elasticity ( $\mathrm{kPa}$ ) using the simple equation $E=3 \rho c^{2}$ ( $E=$ the Young modulus, $\rho=$ tissue density, $c=$ shear wave speed). Today, almost all commercial scanners provide values both in $\mathrm{m} / \mathrm{sec}$ and $\mathrm{kPa}$. However, it is preferable to report values in $\mathrm{m} / \mathrm{sec}$ because it is the quantity directly measured by the machine and the above simple conversion to the Young modulus $(E)$ is accurate only if several assumptions are true [6].

\section{Normal Testes}

The color map of the strain elastogram from a normal testicle demonstrates a central parenchymal green color with blue edges, which is surrounded by red bands (Fig. 1). This is known as a 3-ring structure [7]. Mean shear wave velocities of $0.76 \mathrm{~m} / \mathrm{sec}(95 \%$ confidence interval, 0.75 to $0.78 \mathrm{~m} / \mathrm{sec}$ ) from 130 normal testicles and $1.92 \mathrm{~m} / \mathrm{sec}$ in 19 patients with testicular cancer have been reported by Pedersen et al. [8] and Marcon et al. [9], respectively, both using virtual touch tissue imaging quantification (VTIQ; Siemens Medical Solutions, Mountain View, CA, USA). Furthermore,

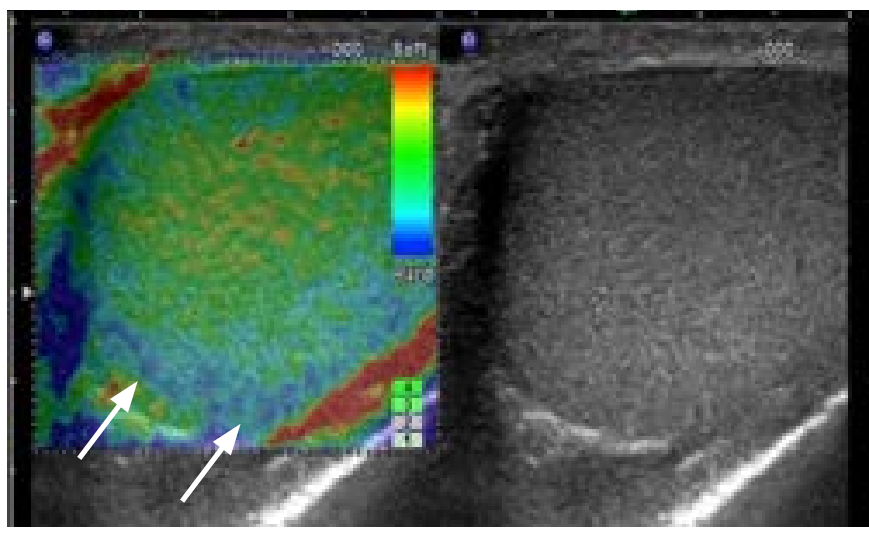

B

Fig. 1. Strain elastography appearance of two patients with normal testes.

A, B. The blue rim on the outside of the normal testis is referred to as a 'boundary' effect (arrows). It is thought to arise because the soft tissue is more 'tethered' at the testicular margin and therefore suffers less deformation when stress is applied. This is demonstrated in an exaggerated fashion in a long-standing atrophied testis (A). 
Trottmann et al. [11] reported that the center of the testis showed significantly lower shear wave velocity than the inferior and superior portion of the testis, through results obtained from 60 healthy testes using SuperSonic Imaging (Aixplorer, Paris, France). Therefore, clinicians may consider using different normal values as references when comparing the results of pathological testicular tissue or focal lesions in different areas. In addition to intra-testicular shear wave velocity variability, a previous study demonstrated significant differences in shear wave velocities measured on different machines [12]. Trottmann et al. [13] showed that values obtained using SuperSonic Imaging were significantly higher than those measured using VTIQ in 58 healthy testes which suggests that shear wave velocity values are not interchangeable across different commercial systems; a similar limitation has been found for the shear wave assessment of liver fibrosis.

\section{Testicular Neoplastic Lesions}

\section{Strain Elastography}

Intra-testicular lesions can be subdivided into malignant neoplasms, benign neoplasms, and non-neoplastic benign lesions. Testicular germ cell tumors account for over $95 \%$ of primary malignant testicular tumors, and they can be further divided into nonseminomatous or seminoma germ cell tumors, which comprise $60 \%$ and $40 \%$ of germ cell tumors, respectively. Testicular seminomas are typically well-defined, homogeneously hypoechoic lesions with no features of local invasion of the tunica albuginea on B-mode US. On strain elastograms, seminomas display a uniformly stiff nature (Fig. 2). Non-seminomatous germ cell tumors include embryonal cell carcinoma, teratoma, choriocarcinoma, and mixed tumors containing more than one histological cell type (Fig. 3). These tumors also display hard tissue stiffness but may have a less homogeneous elastogram map due to their heterogenous cellular structures. Sertoli and Leydig cell tumors are gonadal stromal tumors, which represent approximately $5 \%$ of all testicular neoplasms. The majority of Leydig cell tumors are benign neoplasms; only $10 \%$ of them have been reported to have a malignant potential on histological analysis [14]. Gonadal stromal cell tumors are often small, well-defined focal testicular lesions with reduced reflectivity and frequently show increased peripheral vascularity on color Doppler imaging. Their tissue stiffness can vary from mildly hard to hard on strain elastography (Fig. 4) $[10,15]$. However, their vascularity pattern has

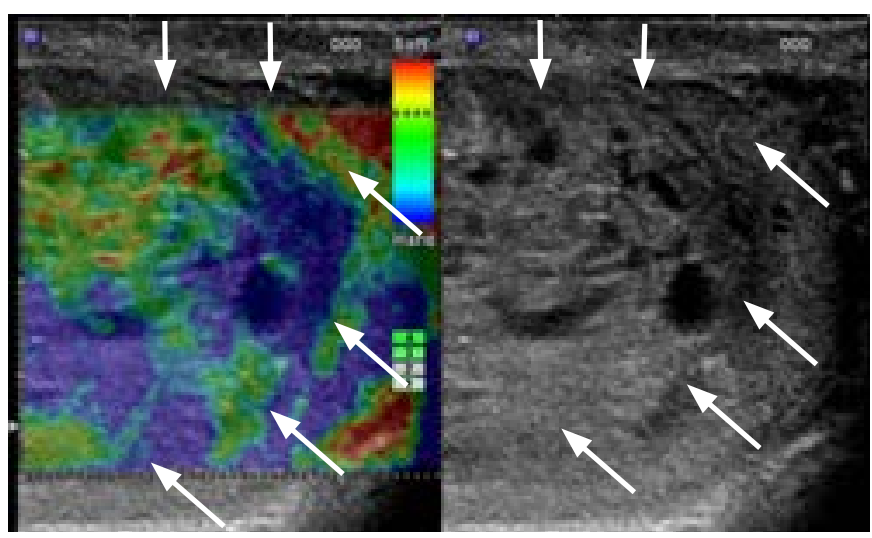

Fig. 3. A mixed non-seminomatous germ cell tumor in a 38-yearold man who presented with a 2-week history of mild testicular discomfort. The B-mode ultrasound image demonstrates a large heterogeneous mass with cystic areas (arrows). On the strain elastography image, the lesion demonstrates predominant hard tissue stiffness, as shown in blue.

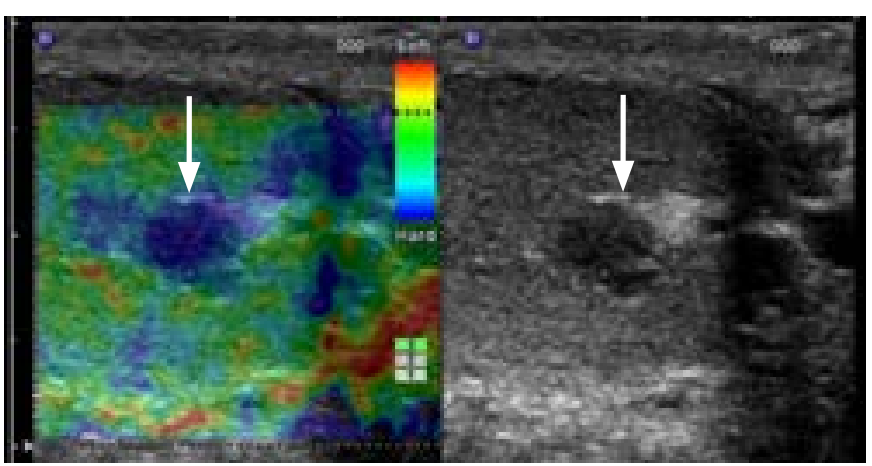

A

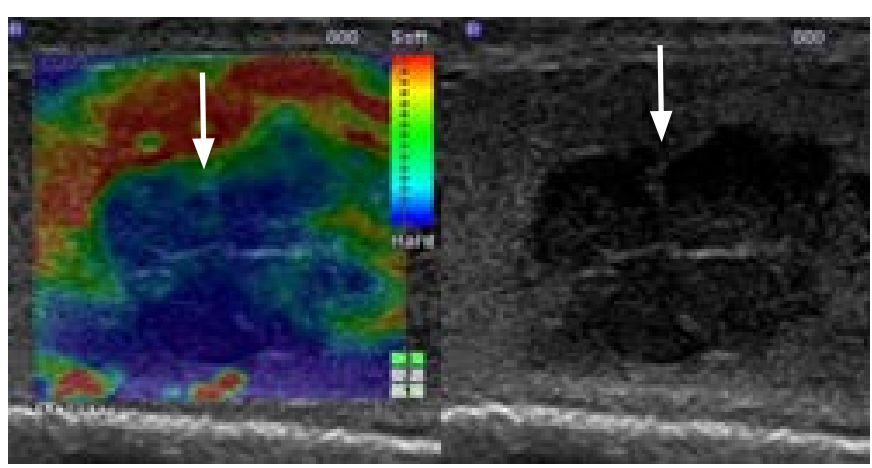

B

Fig. 2. Two examples of testicular seminoma.

A. Incidental finding of a testicular seminoma in a 55-year-old man is shown. Strain elastography and B-mode images demonstrate a small lesion with uniform low reflectivity and uniformly hard tissue stiffness as displayed by the homogeneous blue color within the lesion (arrows). B. A testicular seminoma in a 40-year-old man who presented with left testicular pain is shown. Real-time elastography and B-mode images demonstrate a large multiloculated mass (arrows). On strain elastography, the lesion demonstrates uniformly hard tissue stiffness. 


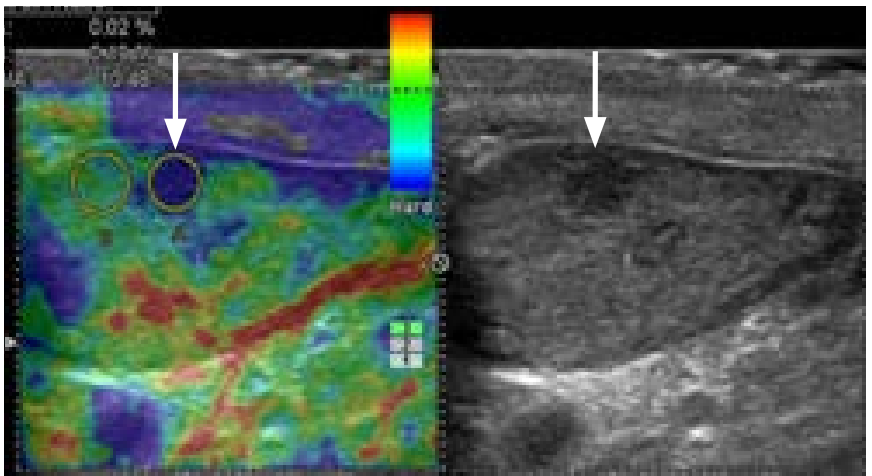

A

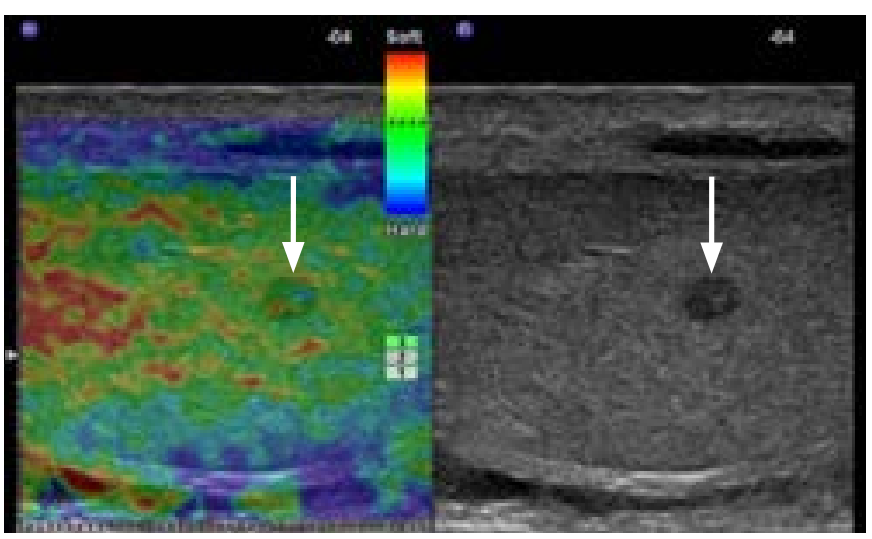

C

been reported to differ from that of germ cell tumors, as gonadal stromal cell tumors show a significantly shorter filling time than germ cell tumors [15] and persist longer than the normal testicular parenchymal enhancement [16]. Primary lymphoma of the testis is rare, with a reported incidence of 0.09 per 100,000, but lymphoma represents the most common testicular malignancy in older men (age $>60$ years) [17]. In a cohort of six patients with histological confirmation of primary testicular lymphoma, all lesions appeared hard; five of six showed a VES of 5, and the other had a VES of 4 (Fig. 5) [18].

Testicular epidermoid and dermoid cysts are the most common benign neoplastic lesions and demonstrate hard elastographic properties $[10,19,20]$. They are often uniformly hard on strain elastography, with SR values often exceeding 40 . However, it is the often-typical B-mode US feature of an "onion ring" configuration of alternating hypoechoic and hyperechoic rings and avascularity on color Doppler US that enable differentiation of epidermoid cysts from malignant lesions (Fig. 6). Testicular hemangioma is a benign rare testicular neoplasm that occurs in the same age group (second to fourth decades) in which primary germ cell tumors predominate (Fig. 7). Bernardo et al. [21] reported a case of capillary hemangioma that demonstrated relatively soft tissue stiffness on strain elastography,

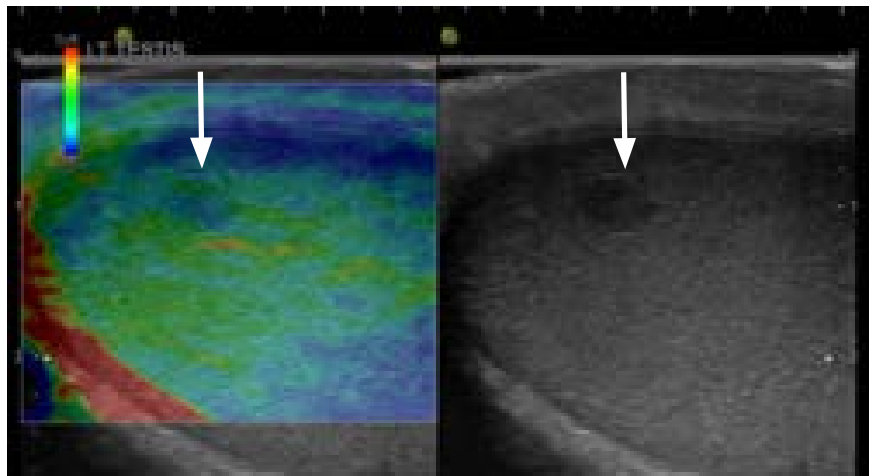

B

Fig. 4. Three examples of Leydig cell tumors.

A. Incidental finding in a 65-year-old man is shown. A small focal low reflective lesion (arrows) is noted to be blue and deemed 'hard' on elastography. B. A 41-year old man who presented with left testicular pain is shown. The lesion (arrows) is a mixture of blue and green, depicting an intermediate "hard" lesion on elastography. C. A 37-year-old man was found to have a lump in his left testicle on physical examination. The lesion demonstrates a green and red lesion, a mildly "hard" lesion on elastography. On B-mode ultrasonography, all three Leydig cell tumors demonstrated the typical appearance of small well-defined lesions with homogeneous low reflectivity (arrows). On tissue elastography (arrow), they can have a variable appearance. They can be hard (A; strain ratio, 10.48) or intermediate/mildly hard $(B, C)$.

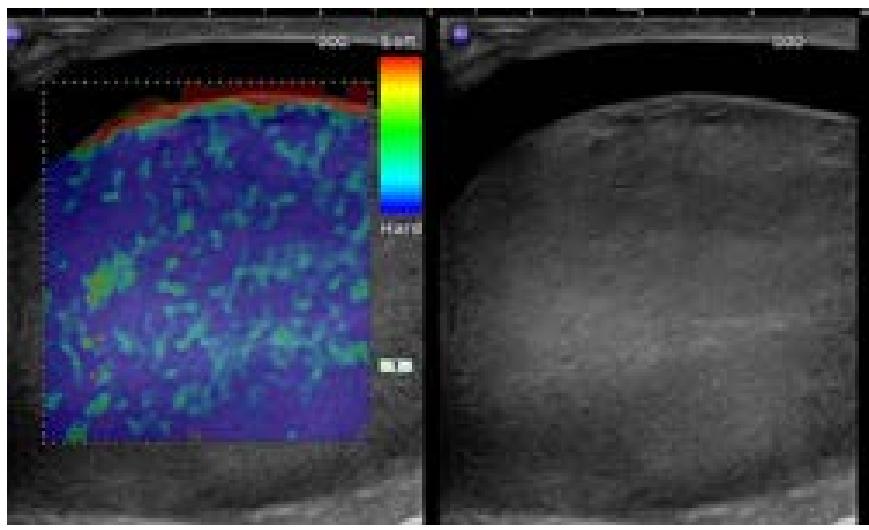

Fig. 5. A testicular lymphoma in an asymptomatic 30-year-old man. On B-mode ultrasonography, the lesion appears as a diffuse enlargement of the testis with decreased echogenicity of the entire testis. On tissue elastography, it appears as an almost uniformly hard lesion.

with a VES of 3 and an SR of 2.3.

A handful of studies have investigated the ability of strain elastography to differentiate malignant neoplasms from benign neoplasms using VES and SR. Whilst hard elastograms, defined based on a VES of $>3$, demonstrate a high sensitivity (81.1\% - 


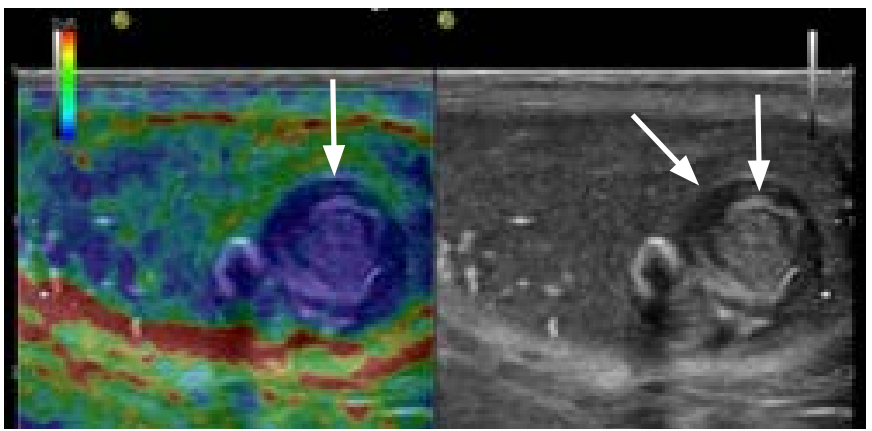

Fig. 6. A testicular epidermoid in a 15-year-old boy with history of microlithiasis. On B-mode ultrasonography, the epidermoid has the typical sonographic features of an "onion ring" configuration with alternating hyperechoic and hypoechoic rings (arrows). The strain elastography color map shows that it was predominantly hard, with the blue color distributed in over $80 \%$ of the abnormality.

$100 \%$ ) in differentiating malignant testicular neoplasms from benign lesions, the specificity varies considerably among studies $(25 \%-98.2 \%)[2,4,10,19,22]$. In a cohort containing 30 testicular neoplasms, Pastore et al. [23] showed that SR provided adjunctive information about tumor characteristics along with B-mode and color Doppler imaging, aiding in the diagnosis of the neoplastic origin of testicular abnormalities. Pozza et al. [4] reported that higher SR values were found in malignant and neoplastic lesions than in benign and non-neoplastic lesions in a cohort comprising 144 testicular lesions. However, SR alone has a limited diagnostic ability to differentiate malignant from benign testicular lesions, with a reported sensitivity of $59.4 \%$ and specificity of $66.6 \%$ using a cutoff SR value of $>1.41$ for malignant lesions [4]. The elasticity score derived from a visual elastogram assessment was found to have a higher diagnostic accuracy (area under the curve [AUC], 0.804) than SR (AUC, 0.631) [4]. However, conflicting results were reported by Konstantatou et al. [10], who found that SR was a significantly better assessment than VES in diagnosing malignant lesions. In their cohort of 86 patients, an SR cut-off value of 3.21 was found to differentiate benign from malignant lesions with an area under the receiver operating characteristic curve of 0.722 [10]. Currently, the role of SR in characterizing testicular lesions is limited. The cutoff value for SR is system-specific and dependent on the prevalence of various aetiologies of the testicular lesions in the study cohort. Whilst some evidence supports the role of strain elastography in differentiating benign from malignant testicular lesions, strain elastography cannot differentiate benign neoplastic from malignant neoplastic lesions. Konstantatou et al. [10] showed that 14 of 17 benign neoplasms and 25 of 31 malignant neoplasms had a VES of 4-6.

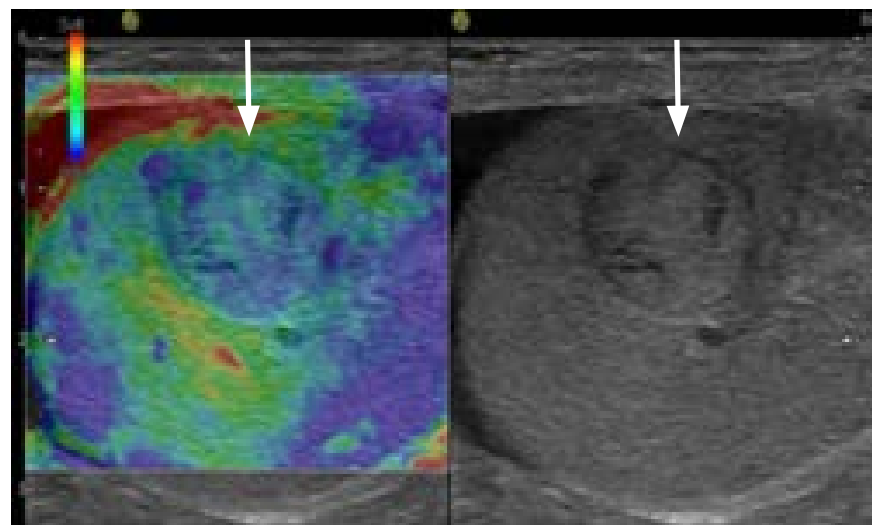

Fig. 7. A testicular capillary haemangioma in a 60-year-old man. The lesion appears relatively homogeneous with slightly increased echogenicity (arrows). The tissue stiffness color map suggests the lesion is relatively soft, with a predominantly green color mixed with some blue areas.

\section{Shear Wave Elastography}

Unlike strain elastography, which is a qualitative assessment of tissue stiffness, shear wave elastography provides a quantitative assessment by measuring the shear wave velocity. A preliminary study involving 15 testicular germ cell tumors showed significantly higher shear wave velocities in seminomas (mean, $10.6 \mathrm{kPa}$; range, 4.5 to $15.8 \mathrm{kPa}$ ) than in non-seminomatous germ cell tumors (mean, $47.0 \mathrm{kPa}$; range, 29.0 to $65.5 \mathrm{kPa}$ ) [24]. The authors postulated that the difference in shear wave velocities may have been due to differences in histologic features between the seminomas and nonseminomas, as non-seminoma tumors consist of undifferentiated cells with a prominent stromal component, some of which may contain cartilage or bony components [24]. A cohort study by Rocher et al. described the multiparametric testicular US features of 10 burnt-out testicular tumors, for which much higher tissue stiffness was demonstrated compared to the surrounding tissue (13 $\mathrm{kPa}$ vs. $2 \mathrm{kPa}$ ) using shear wave elastography (Supersonic Imaging, Aix-en-Provence, France) [25]. Increased tissue stiffness could not distinguish burnt-out tumors from residual tumors. The diagnosis of a burnt-out tumor may be suspected in the presence no or very poor enhancement of the tissue on contrast-enhanced US. Currently, only a single study has investigated the value of shear wave velocity in characterizing neoplastic testicular lesions [24].

\section{Testicular Non-neoplastic Lesions}

\section{Strain Elastography}

A variety of non-neoplastic intratesticular abnormalities may present as focal intra-testicular abnormalities, causing a diagnostic conundrum. These indeterminate tumor-like lesions include focal 
abscesses, prominent retia testis, hematomas [3], segmental testicular infarctions [26,27], venous infarctions [28], focal orchitis, and sarcoidosis [16]. The majority of non-neoplastic testicular lesions do not require surgical management, unlike the majority of neoplastic lesions, for which orchidectomy or testicular-sparing surgery is essential. Therefore, the ability to differentiate these benign lesions from malignant lesions on imaging is of paramount importance if orchidectomy is to be avoided.

Several cohort studies have tried to compare the tissue elasticity of non-neoplastic lesions with that of neoplastic lesions. In general, non-neoplastic lesions appear softer than neoplastic lesions. Konstantatou et al. [10] showed that the median SR for

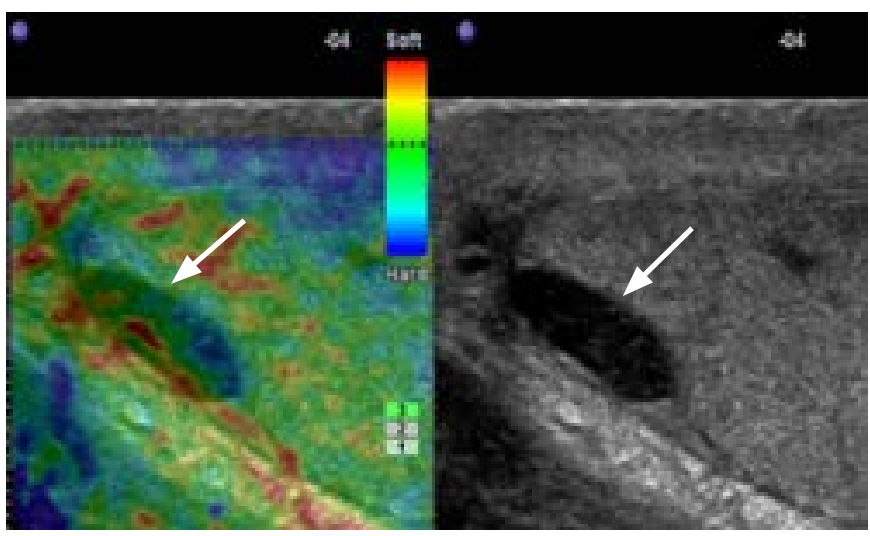

Fig. 8. A testicular hematoma in a 30-year-old man who presented with persistent right testicular pain. The lesion is oval-shaped with low echogenicity located in the periphery of the testis (arrows). The strain elastography color map shows a soft lesion, as indicated by the green color in over $80 \%$ of the lesion with a scattered red color. non-neoplastic lesions was 1.95 , compared to 4.64 and 3.78 for neoplastic malignant and neoplastic benign lesions. Aigner et al. [29] showed that $100 \%$ of cases of orchitis $(n=6), 75 \%$ of cysts $(n=4)$ and $80 \%$ of partial testicular infarctions $(n=5)$ were soft on strain elastography. Several case reports and case series have reported strain elastography findings for non-neoplastic lesions, such as segmental testicular infarctions, testicular hematomas [3], abscesses, atypical retia testis, and cysts. Intra-testicular hematoma is often a consequence of trauma, although upon presentation patients often have no recollection of injury (Fig. 8). Yusuf et al. [3] evaluated a cohort of 16 hematomas with strain elastography, 13 of which had a VES of 3 and the reported mean SR was 1.19 (range, 0.41 to 2.36). Intra-testicular hematomas are often soft lesions in a sub-capsular position. Segmental testicular infarction is a rare cause of testicular pain and discomfort. Its B-mode US and tissue elastography features depend on the timing of sonographic examination after the trauma. The area of the abnormality may initially show soft characteristics due to the presence of swelling and increased water content. As it evolves, the area may demonstrate hard features on an elastography color map (Fig. 9). Focal orchitis may also present as an indeterminate testicular lump. On B-mode US, it appears as an ill-defined abnormality with reduced echogenicity. Ancillary findings may include hydrocele or epididymitis. The area of abnormality is often hypervascular on color Doppler. On strain elastography, the abnormality initially appears as a hard lesion, but as it evolves it becomes softer (Fig. 10). Testicular torsion leads to an ischemic insult to the testes; it is a surgical emergency if it presents acutely, and a sonographic investigation should not be attempted, particularly if it causes delay in surgical exploration. However, US has a role in differentiating delayed presentation of testicular torsion

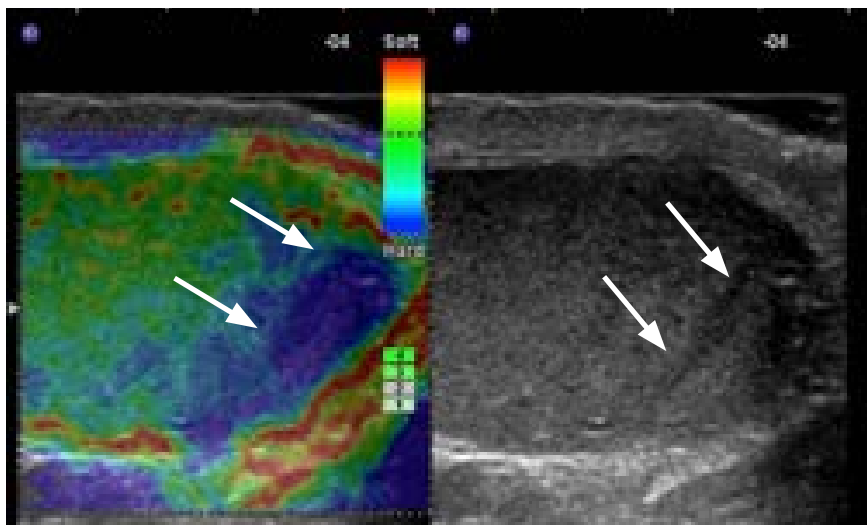

B

A

Fig. 9. Testicular segmental infarction in a 27-year-old man who presented with a 2-day history of testicular pain and discomfort.

A. On B-mode ultrasonography, at presentation, the lesion appears as a peripheral wedge-shaped area with slightly reduced echogenicity (arrow). On a strain elastography color map, the lesion appears as a soft lesion, as indicated by the predominant green color (arrow). B. Two weeks later, the lesion had evolved, becoming hard, as shown by the predominant blue color (arrows). 


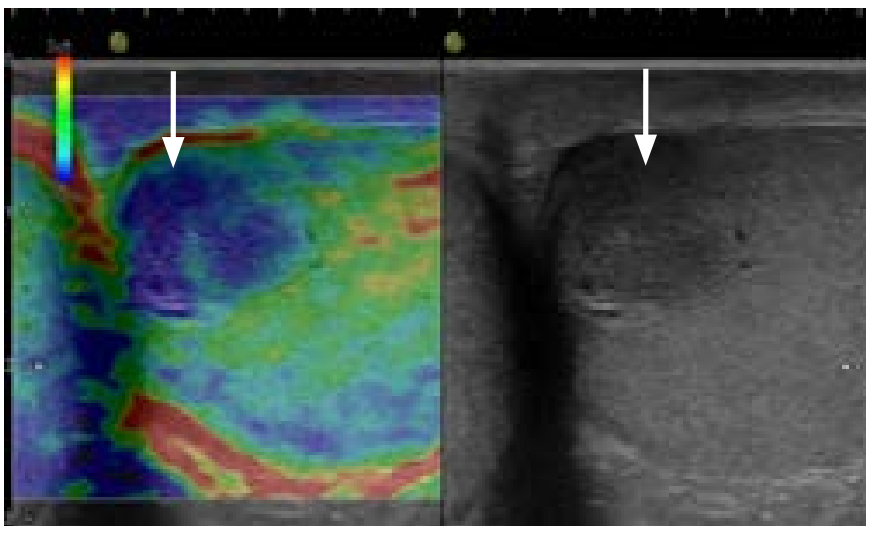

A

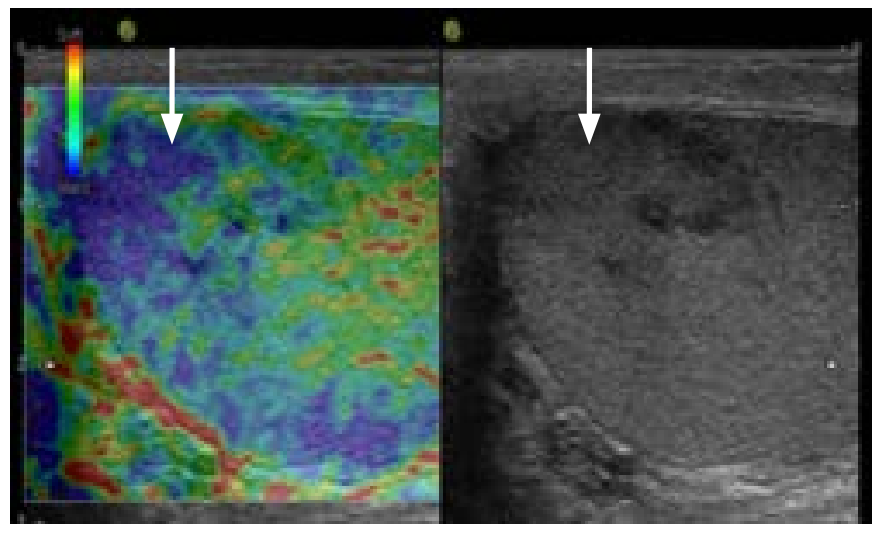

B

Fig. 10. Focal orchitis in a 31-year-old man who presented with a testicular lump.

A. On B-mode ultrasonography (US), the lesion appears as an ill-defined area of reduced echogenicity (arrow) with associated features such as thickening of the epididymis and presence of a small hydrocele. On strain elastography color map, it appeared initially as a hard lesion (arrow). B. Ten days later, the lesion was less obvious on B-mode US (arrow) and became less hard (arrow) on follow-up imaging.

from other pathologies. By comparing the pathological evaluation of the surgical specimen with pre-operative testicular torsion at different time points and different degrees of torsion, Herek et al. [30] showed that testicular tissue stiffness gradually increased from $360^{\circ}$ to $720^{\circ}$ of torsion and became softer at $1,080^{\circ}$, where necrosis occurred and damage to the testes became irreversible. They also showed that the contralateral testis was also affected and presented increased tissue stiffness. Therefore, in cases of partial torsion where testicular viability and salvageability of the testis is in question, strain elastography of the testis may add additional benefit to a color Doppler US examination [30]. Non-neoplastic testicular lesions tend to be softer than their neoplastic counterparts. However, Konstantaou et al. [10] found that 16 of 38 lesions had a VES of $4(n=4), 5(n=7)$, or $6(n=5)$, indicating there is significant overlap between the tissue stiffness of neoplastic and non-neoplastic lesions.

\section{Shear Wave Elastography}

A shear wave elasticity value of $1.7 \mathrm{kPa}$ using the SuperSonic Imagine apparatus (Aixplorer Provence) was described in a case report of a segmental testicular infarction, compared to an elasticity value of $2.6 \mathrm{kPa}$ in the adjacent normal testicular parenchyma [31]. A study of 248 patients including 130 with normal testicular tissue, 99 with microlithiasis, and 19 with testicular cancer showed that the mean shear wave velocity from three measurements taken from the centre, upper pole, and lower pole of the testis or testicular lesion was significantly higher in patients with testicular cancer (mean velocity, $1.92 \mathrm{~m} / \mathrm{sec}$ ) than in those with normal testicular tissue $(0.76$ $\mathrm{m} / \mathrm{sec}$ ) or testicular microlithiasis $(0.79 \mathrm{~m} / \mathrm{sec})[8]$.

\section{Conclusion}

Strain or shear wave elastography allows further characterization of tissue stiffness on US. It has been shown that neoplastic lesions are harder than non-neoplastic lesions, and malignant neoplastic lesions are harder than neoplastic benign lesions. However, significant overlap exists between types of lesions. Assessment of the B-mode US appearance, lesion vasculature with color Doppler US, and contrast-enhanced US in addition to tissue elastography as part of a multiparametric ultrasound examination [32] is indispensable for increasing diagnostic accuracy and confidence when placing indeterminate lesions under surveillance or subjecting the patient to surgery [16].

ORCID: Cheng Fang: https://orcid.org/0000-0001-9649-8904; Dean Y. Huang: https:// orcid.org/0000-0002-5637-6723; Paul S. Sidhu: https://orcid.org/0000-0003-19284077

\section{Author Contributions}

Conceptualization: Fang C, Huang DY, Sidhu PS. Data acquisition: Fang C, Huang DY, Sidhu PS. Data analysis or interpretation: Fang C, Huang DY, Sidhu PS. Drafting of the manuscript: Fang C, Huang DY, Sidhu PS. Critical revision of the manuscript: Fang C, Huang DY, Sidhu PS. Approval of the final version of the manuscript: all authors.

\section{Conflict of Interest}

No potential conflict of interest relevant to this article was reported. 


\section{References}

1. Itoh A, Ueno E, Tohno E, Kamma H, Takahashi H, Shiina T, et al. Breast disease: clinical application of US elastography for diagnosis. Radiology 2006;239:341-350.

2. Goddi A, Sacchi A, Magistretti G, Almolla J, Salvadore M. Real-time tissue elastography for testicular lesion assessment. Eur Radiol 2012;22:721-730.

3. Yusuf G, Konstantatou E, Sellars ME, Huang DY, Sidhu PS. Multiparametric sonography of testicular hematomas: features on grayscale, color Doppler, and contrast-enhanced sonography and strain elastography. J Ultrasound Med 2015;34:1319-1328.

4. Pozza C, Gianfrilli D, Fattorini G, Giannetta E, Barbagallo F, Nicolai E, et al. Diagnostic value of qualitative and strain ratio elastography in the differential diagnosis of non-palpable testicular lesions. Andrology 2016;4:1193-1203.

5. Bamber J, Cosgrove D, Dietrich CF, Fromageau J, Bojunga J,

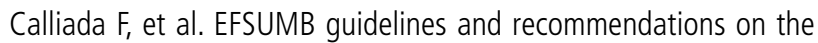
clinical use of ultrasound elastography. Part 1: Basic principles and technology. Ultraschall Med 2013;34:169-184.

6. Dietrich CF, Bamber J, Berzigotti A, Bota S, Cantisani V, Castera L, et al. EFSUMB guidelines and recommendations on the clinical use of liver ultrasound elastography, update 2017 (long version). Ultraschall Med 2017;38:e16-e47.

7. Zeng B, Chen F, Qiu S, Luo Y, Zhu Z, Chen R, et al. Application of quasistatic ultrasound elastography for examination of scrotal lesions. J Ultrasound Med 2016;35:253-261.

8. Pedersen MR, Moller H, Osther PJ, Vedsted P, Holst R, Rafaelsen SR. Comparison of tissue stiffness using shear wave elastography in men with normal testicular tissue, testicular microlithiasis and testicular cancer. Ultrasound Int Open 2017;3:E150-E155.

9. Marcon J, Trottmann M, Rubenthaler J, Stief CG, Reiser MF, Clevert DA. Shear wave elastography of the testes in a healthy study collective: differences in standard values between ARFI and VTIQ techniques. Clin Hemorheol Microcirc 2016;64:721-728.

10. Konstantatou E, Fang C, Romanos O, Derchi LE, Bertolotto M, Valentino $M$, et al. Evaluation of intratesticular lesions with strain elastography using strain ratio and color map visual grading: differentiation of neoplastic and nonneoplastic lesions. J Ultrasound Med 2019;38:223-232.

11. Trottmann M, Marcon J, D'Anastasi M, Bruce MF, Stief CG, Reiser $M F$, et al. Shear-wave elastography of the testis in the healthy man: determination of standard values. Clin Hemorheol Microcirc 2016;62:273-281.

12. Shin HJ, Kim MJ, Kim HY, Roh YH, Lee MJ. Comparison of shear wave velocities on ultrasound elastography between different machines, transducers, and acquisition depths: a phantom study. Eur Radiol 2016;26:3361-3367.

13. Trottmann M, Rubenthaler J, Marcon J, Stief CG, Reiser MF, Clevert
DA. Differences of standard values of Supersonic shear imaging and ARFI technique: in vivo study of testicular tissue. Clin Hemorheol Microcirc 2016;64:729-733.

14. Papatsoris AG, Triantafyllidis A, Gekas A, Karamouzis MV, Rosenbaum T. Leydig cell tumor of the testis. New cases and review of the current literature. Tumori 2004;90:422-423.

15. Lock G, Schroder C, Schmidt C, Anheuser P, Loening T, Dieckmann KP. Contrast-enhanced ultrasound and real-time elastography for the diagnosis of benign Leydig cell tumors of the testis: a single center report on 13 cases. Ultraschall Med 2014;35:534-539.

16. Huang DY, Sidhu PS. Focal testicular lesions: colour Doppler ultrasound, contrast-enhanced ultrasound and tissue elastography as adjuvants to the diagnosis. Br J Radiol 2012;85 Spec No 1:S41-S53.

17. Gundrum JD, Mathiason MA, Moore DB, Go RS. Primary testicular diffuse large B-cell lymphoma: a population-based study on the incidence, natural history, and survival comparison with primary nodal counterpart before and after the introduction of rituximab. J Clin Oncol 2009;27:5227-5232.

18. Kachramanoglou C, Rafailidis V, Philippidou M, Bertolotto M, Huang DY, Deganello A, et al. Multiparametric sonography of hematologic malignancies of the testis: grayscale, color Doppler, and contrastenhanced ultrasound and strain elastographic appearances with histologic correlation. J Ultrasound Med 2017;36:409-420.

19. Auer T, De Zordo T, Dejaco C, Gruber L, Pichler R, Jaschke W, et al. Value of multiparametric US in the assessment of intratesticular lesions. Radiology 2017;285:640-649.

20. Patel K, Sellars ME, Clarke JL, Sidhu PS. Features of testicular epidermoid cysts on contrast-enhanced sonography and real-time tissue elastography. J Ultrasound Med 2012;31:115-122.

21. Bernardo S, Konstantatou E, Huang DY, Deganello A, Philippidou M, Brown $C$, et al. Multiparametric sonographic imaging of a capillary hemangioma of the testis: appearances on gray-scale, color Doppler, contrast-enhanced ultrasound and strain elastography. J Ultrasound 2016;19:35-39.

22. Marsaud A, Durand M, Raffaelli C, Carpentier X, Rouscoff $Y$, Tibi B, et al. Elastography shows promise in testicular cancer detection. Prog Urol 2015;25:75-82.

23. Pastore AL, Palleschi G, Maceroni P, Manfredonia G, Autieri D, Cacciotti J, et al. Correlation between semiquantitative sonoelastography and immunohistochemistry in the evaluation of testicular focal lesions. Cancer Imaging 2014;14:29.

24. Dikici AS, Er ME, Alis D, Samanci C, Ustabasioglu FE, Demirdag $C$, et al. Is there any difference between seminomas and nonseminomatous germ cell tumors on shear wave elastography? A preliminary study. J Ultrasound Med 2016;35:2575-2580.

25. Rocher L, Glas L, Bellin MF, Ferlicot S, Izard V, Benoit G, et al. Burned-out testis tumors in asymptomatic infertile men: multiparametric sonography and MRI findings. J Ultrasound Med 
2017:36:821-831.

26. Bilagi P, Sriprasad S, Clarke JL, Sellars ME, Muir GH, Sidhu PS. Clinical and ultrasound features of segmental testicular infarction: six-year experience from a single centre. Eur Radiol 2007;17:28102818.

27. Bertolotto M, Derchi LE, Sidhu PS, Serafini G, Valentino M, Grenier $\mathrm{N}$, et al. Acute segmental testicular infarction at contrast-enhanced ultrasound: early features and changes during follow-up. AJR Am J Roentgenol 2011;196:834-841.

28. Lung PF, Jaffer OS, Sellars ME, Sriprasad S, Kooiman GG, Sidhu PS. Contrast-enhanced ultrasound in the evaluation of focal testicular complications secondary to epididymitis. AJR Am J Roentgenol 2012;199:W345-W354.
29. Aigner $F$, De Zordo T, Pallwein-Prettner L, Junker D, Schafer $G$, Pichler $R$, et al. Real-time sonoelastography for the evaluation of testicular lesions. Radiology 2012;263:584-589.

30. Herek D, Herek O, Akbulut M, Ufuk F. Role of Strain elastography in the evaluation of testicular torsion: an experimental study. J Ultrasound Med 2016;35:2149-2158.

31. Kantarci F, Cebi Olgun D, Mihmanli I. Shear-wave elastography of segmental infarction of the testis. Korean J Radiol 2012;13:820822.

32. Sidhu PS. Multiparametric Ultrasound (MPUS) imaging: terminology describing the many aspects of ultrasonography. Ultraschall Med 2015;36:315-317. 